\title{
BACKGROUND AND SUBSTANCE OF DETECTION OF ECOLOGICAL CONFLICTS IN THE ECONOMY
}

\author{
Nataliia CHUPRYNA ${ }^{1}$ \\ Ukrainian State University of Chemical Technology, Ukraine
}

\begin{abstract}
The purpose of the paper is to study the nature of ecological conflicts in the economy, which, subject to globalization enable (or impossible) to solve pollution and the destruction of all elements of the environment. Identify ecological conflicts in the economy borders, which will be decisive in shaping their capabilities and develop alternatives to overcome ecological conflicts. Methodology. The study is based on an analysis of the state of the ecological component of the Ukrainian economy in recent years and the results of the country's industrial enterprises. The work of industrial enterprises may provoke the creation of ecological conflicts. Research findings of leading scientists in this field are also used. Results of the research have made it possible to determine the nature of the identification of ecological conflicts in the economy. Ensure the development and dissemination of ecological conflicts in the dynamics. Developed by constructing a map of ecological conflicts makes it possible to analyze the components of ecological conflicts in more detail and to develop management actions aimed at eliminating environmental conflict in the economy. The necessity of engaging potential ecological conflicts in the future by setting its limits in the economy. Practical implications. Environmental problem, namely a warning or ecological conflicts optimal solution is a prerequisite for the country's development as an integral state with a healthy population that can live in the country and to use its resources freely (within the legislation). However, overcoming ecological conflicts not paid enough attention to both at the state and local level. The main stages of analysis and possible options for the development ecological conflicts become the basis for the formation of government priorities towards the greening of the main industries in the economy. Features of occurrence of each individual environmental conflict, the implementation of research on this issue, systematization and analysis of the results and ways to overcome ecological conflicts in industrialized countries - it should be one of the main priorities of the state, and implemented, both at micro and macro levels in the economy. When considering the greening process, the development and management of the ecological security of the state is necessary to describe manifestations ecological conflicts enough, their functions and characteristics. The intervention of the state in addressing ecological conflicts should not only lead to its solution, but also provide the possibility of co-existence and further development of all participants in ecological conflicts in the economy. Value/originality. Thus, we can determine that the development and overcoming ecological conflicts in modern conditions depends on the economic and political situation in the country. Map construction of ecological conflicts makes it possible to take advantage of the positive potential of ecological conflicts for the development potential of the region. Assessing the scope of the conflict, it will reduce the economic cost of its solutions.
\end{abstract}

Key words: ecological conflicts in the economy, industrial companies, subject, ecological problems, conflict solution.

JEL Classification: M38, Q57

\section{1. Введение}

На сегодняшний Аень в Украине, как в стране, в которой: функционируют крупные промышленные преАприятия химической, метамургической и Аругих отраслей производства; сельскохозяйственной стране, на площаАях обрабатываемых земель используются размичные виды агрохимических добавок; применяются пищевые Аобавки при разведении сельхоз животных, существует не только угроза возникновения экологических конфликтов, а уже и практика их преодоления. К сожалению, решение экоконфмиктов в Украине не всегАа явмяется эффективной, а иногАа Ааже существование экоконфликтов не определено, как местными органами вцасти, так и на государственном уровне.

Вопросам экоконфликтов и методик их решения посвящены работы таких известных ученых, как

Corresponding author:

${ }^{1}$ Department of Marketing, Ukrainian State University of Chemical Technology.

E-mail: chupryna_n_n@mail.ru 
О. Балацький, Б. Буркинський, О. Веклич, В. Салабаш, В. Степанов, С. Харичков, М. Петрушенко, С. Харичков, К. Гофман, А. Гусев, М. Федоренко, Т. Гомер-Аиксон, Г. Бехлер, К. Шпильман, С. Мейсон, А. Шпринц, Н. ГАеАич, И. Янга, $\Lambda$. Хенс и Ар.

\section{2. ПреАПосылки возникновения экомогических конфАиктов}

Аля эффективного управления экологической ситуацией в стране нужно проводить политику, которая нацелена на экологизацию страны в целом. В этой политике необходимо достаточно четко определить экологическую направленность промышиенных преАприятий, как в рамках региона, так и в рамках страны в целом (Chuprina, 2015). Необходимо отметить, что существует обратнопропорциональная зависимость межАу экологической составляющей и ростом промышиенного производства. То есть фактически сформировался принцип их взаимодействия в условиях глобамизации, а именно: экологическая ситуация в стране ухудшается с интенсивным ростом объемов произвоАства промышиенных предприятий. И, наоборот, падение производственной активности преАприятий промышиенности, и, как слеАствие, кризисное положение экономики страны, но экологическая составцяющая укучшается (рис. 1). ОАнако, если анализировать ситуацию взаимодействия экоконфликтов и результатов работы преАприятий промышменности, то мы можем опредемить существование прямо пропорциональной зависимости, то есть увеличение объемов производства приводит к повышению экоконфмиктов.

ОАним из приоритетов развития экономики страны (особенно в промышиенно ориентированных странах) является обязательным учет такого фактора, как экологическая составцяющая. Безусловно, пересечение всех интересов в этой области может привести к возникновению экоконфликтов. Отсутствие однозначного подхода к определению экоконфликтов и невозможность применения неаАаптированного к условиям Украины Подходов к их оПреАелению и рахрешению приводит к необхоАимости собственных отечественных разработок в этой сфере. При этом нужно учитывать опыт решения экологических проблем Аругих стран (Martinez-Alier, 2002;
J. Linking 2009; Michelot, 2013; Martinez-Alier, J. 2010; Daly, 2015).

По определению многих ученых, конфликт - это норма сосуществования $ю$ юй в социуме. Именно поэтому, мы можем отметить, что в индустриальном обществе экологические конфликты неизбежны. То есть оптимального выхода из этой ситуации и альтернативных путей ее развития почти не существует в современных конкурентных условиях. Но анализ и могика выхода из экоконфликтов на базе применения тактических и стратегических подходов может Аать возможность успешно воспользоваться результатами экоконфииктов.

Сущность экоконфликтов заключается в столкновении интересов Авух основных игроков: природы, как таковой, и человека. Государство в этом виде конфмиктов играет Аве основные функции:

Во-первых, она может быть причиной конфмикта, из-за несовершенства нормативно-правовых актов, политических, социальных, Аемографических, культурных и Аругих факторов.

Во-вторых, может прекратить или разрешить экомогический конфмикт путем применения инструментов государственного воздействия. Эти инструменты могут иметь как Аипломатический, так и силовой

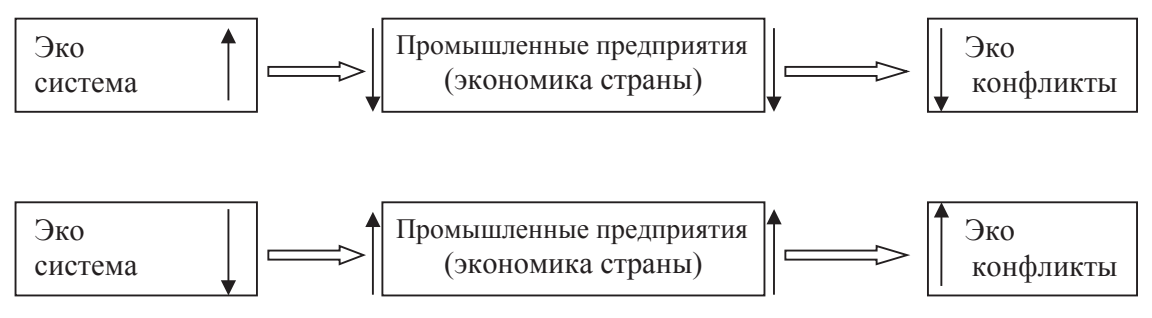

Рис. 1. Взаимодействия экологических и промышиенных составАяющих

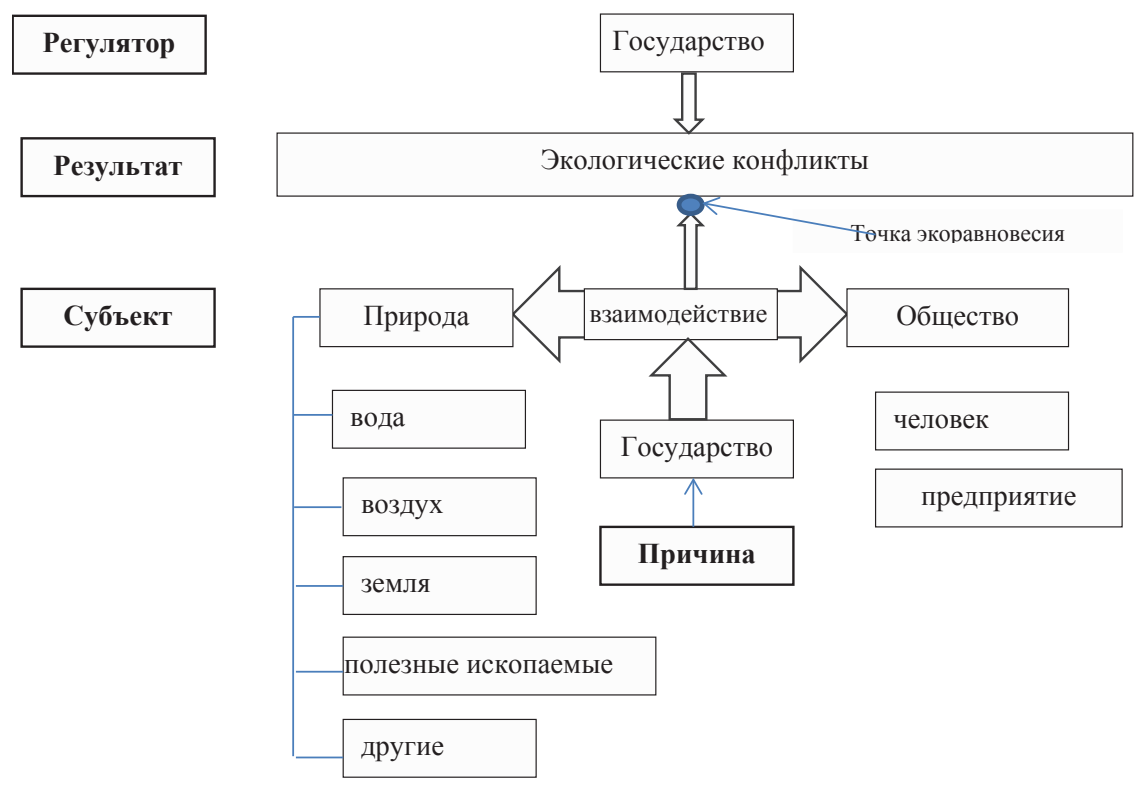

Рис. 2. Сущность возникновения экоконфмикта 
характер. Выбор того или иного инструмента влияния зависит от уровня развития и степени обострения экоконфмиктов, условия его формирования и становления, а так же его место в системе экобезопасности страны. ОАнако выбор оАного из этих инструментов (или их комплексное применение) должно быть обосновано. В частности, обосновывается выбор инструмента воздействия (или их взаимодействие) и возможные направления и альтернативные варианты развития событий, как с позиции госуАарства, так и с позиции участников экоконфмиктов. Исследуется влияние госуАарства с позиции роста национамьной экономики и имиАжа страны (рис. 2).

При вмешательстве государства должны быть учтены интересы участников конфликта, а путь его преодоления привести к Аальнейшему экономическому и экологическому развитию государства. С позиции возникновения и преодоления экоконфликтов необходимо определить поэтапную трансформацию экоконфмиктов, что влияет на состояние окружающей среАы и формирует новое, усовершенствованное развитие промышкенного преАприятия. Эта трансформация и степень зависимости участников экоконфликта Аруг от Аруга, и, как следствие, является Аемонстрацией их возможного сотрудничества или сосуществования. Это сотрудничество (сосуществование) явмяется достаточно сложным элементом взаимоАействия и оАним из путей решения экоконфликтов. Оно может характеризовать особенности взаимодействия участников экоконфликта, взаимоотношения их интересов и приоритетов, которое Аостигается в точке «Экологического равновесия».

Точка экологического равновесия - это когда нахоАится оптимацьное решение Аля всех участников экомогического конфликта. Характеризуя особенности состояния взаимодействия всех участников экоконфликта (включая государство). Применение новых прогрессивных методов управления Аают возможность находиться в точке экологического равновесия или приблизиться к ней. Развитие экоконфмиктов и Аостижения точки экоравновесия в кажАом отАельном случае имеет свои особенности, характеризующиеся специфическими условиями, в которых находятся участники экоконфликтов. Но, Аостаточно важно, на современном этапе развития, не только преодоления экоконфликтов, а то время, когАа система находится в точке экоравновесия, и, по возможности, увемичить этот срок всеми возможными среАствами. И именно в этом, необходимо вмешательство государства.

Необходимо заметить, что на государство, как механизм урегулирования экологических конфликтов может вмиять много факторов, которые перемещают решения конфликта с точки «экоравновесия» в сторону ики общества, или природы. К таким факторам мы можем отнести: экономические, социальные, политические, Аемографические, научно-технические, нормативно-правовые и Аругие. Точка «экоравновесия» - это не всегАа оптимальное решение решения экоконфмиктов:

1. КогАа речь иАет о жизни, зАоровье нации и возможные кризисные послеАствия Аля природы решения экоконфликтов, то Аоминирование интересов экосистемы Аолжно играть решающую роль в решении экоконфмиктов госуаарством.

2. ИногАа, Аля развития общества, науки и техники, экономически обоснованно может быть решение экомогических конфликтов и в интересах общества, но, со временем, необходимо будет кардинально изменить этот Аисбаланс, чтобы такое решение не привело к экомогическому кризису.

\section{3. Сущность карты построения экоконфмиктов}

Но, несмотря на то, что в начальный период времени $\left(t_{0}\right)$ может быть принято решение в пользу того или иного субъекта экоконфмикта в Аинамике, в оптимальном случае будет достигнута «точка экоравновесия», что Аелает невозможным Аоминирование оАного из субъектов экоконфликта (рис. 3).

Классификация конфликтов, преАложенная в работе (Emelyanenko, 2003) Аает возможность разработать «карту построения экоконфликтов». Карта построения экоконфликтов дает наглядное виАение вариантов альтернатив проявления экоконфликтов по признакам. Это Аает возможность разработать прогрессивные среАства и принципиально новые управленческие схемы, которые приведут к более оптимацьного пути решения екоконфмиктив, рост количественных и качественных показателей экономики в целом. Задействование новой схемы управмения экоконфликтами необходимо рассмотреть как фактор объединения всех участников экоконфликта Аля выхода на новый, усовершенствованный уровень функционирования (рис. 4).

Исходя из рисунка 4 мы можем видеть, что существует много моделей построения экоконфликтов. Именно поэтому, при решении кажАого отАельного экоконфмикта необходимо строить свою уникальную

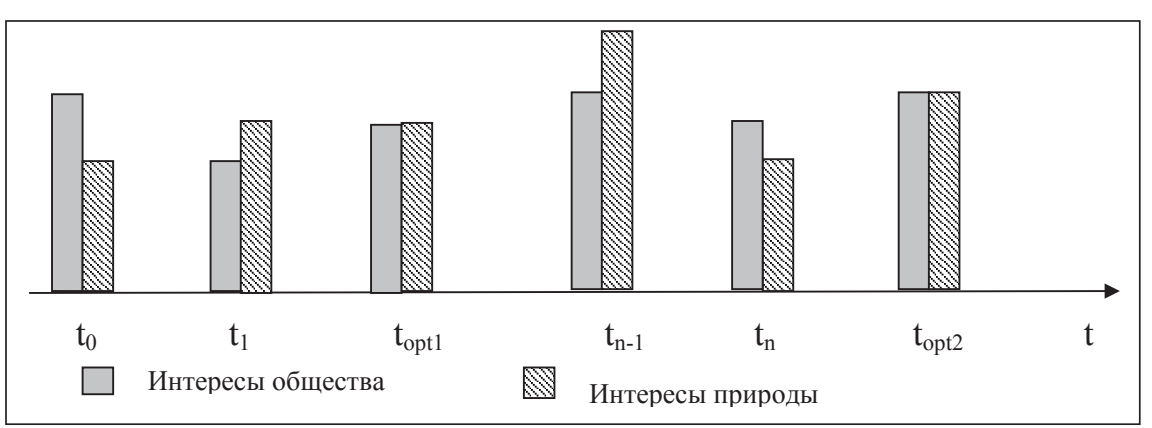

Рис. 3. Развитие в Аинамике и решения экоконфмиктов 


\begin{tabular}{|c|c|c|c|c|}
\hline & \multicolumn{4}{|c|}{ Альтернативные проявления } \\
\hline \multirow{5}{*}{ 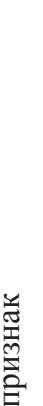 } & Способ решения & правовые & & $\begin{array}{l}\text { ненасильственны } \\
\text { е }\end{array}$ \\
\hline & $\begin{array}{l}\text { Сфера проявления } \\
\text { экоконфликта }\end{array}$ & экономические & & научные \\
\hline & Направленность влияния & вертикальные & горизонғальные & латеральные \\
\hline & Степень выраженности & открытые & скрытые & смешанные \\
\hline & Количество участников & внутренние & межличностные & межгрупповые \\
\hline
\end{tabular}

Рис. 4. Карта построения экоконфмиктов

концепцию из данной ситуации. Экоконфмикты могут отличаться по признакам и альтернативам их проявления: способам решения и сферы проявмения экоконфликтов, направленностью воздействия, количеством участников.

По определению В.В. Сабадаш, екоконфликты - это конфиикт по поводу вцадения, распоряжения природным ресурсом (Sabadash, 2012). Но необходимо, по нашему мнению, еще отметить, что в современных условиях глобализации экоконфликты - это еще и возможность (или невозможность) избежать проблемы загрязнения и уничтожения окружающей среды, а именно водных, земельных, биологических и Аругих ресурсов.

Необходимо, также, отметить, что разные авторы по-разному выделяют основную характеристику конфликтов. Так Вишнякова Н.Ф., Бацабанова А.В., Савемьева К.В., Корзун В.А. считают, что конфликт это столкновение, противостояние и противоречие, но с точки зрения Аругих авторов, таких как, Пиренн М.И., Уткин 3.И., считают, что конфликт - это ситуация, несовместимость; Скибинская А.И. - стремление, Аожкин Г.В. - адаптационная реакция, Ворожейкин И.Е., Кибалов Я., Захаров А.К. - конфликт - это нормальное проявмение социальных связей; Анцупов А.Я., Шипимов А.И. - способ решения. Основываясь на исследованиях ученых, мы можем видеть самые разные подходы к определению конфмикта, говорит о неоднозначной и сложной природе конфликта, а из-за этого и методов его решения. Экоконфмикт не является исключением из этого вывоАа, так как явАяется оАной из разновиАностей конфмиктов вообще.

Аостаточно внимания удемил Петрушенко М.M. моделированию экоконфликтов, что по нашему мнению Аает возможность оценить экоконфмикт и его послеАствия в Аенежном эквиваленте (Petrushenko, 2012) и обеспечить управление экологическими рисками (Anghelache, 2011).

\section{4. Опредемение границ экоконфмиктов}

Аля Аальнейшего изучения и анализа экоконфмиктов, а также Аля их эффективного преодоления необходимо указать границы экологического конфмикта. Это позволит:
- уменьшить время развития и преодоления послеАствий экоконфмиктов;

- задействовать новые формы сотрудничества между участниками экоконфмиктов;

- стимулировать применение новых методов управмения Аля обеспечения выхода из экоконфмиктов и при преодолении его послеАствий;

- обоснованно подойти к оценке выгоА и затрат Аля кажАого из участников экоконфииктов;

- учесть, какие нормативно - правовые акты могут быть задействованы на Аанной территории Амя преодомения как самого экоконфмикта, так и его последствий.

Границы экологических конфмиктов могут быть очерчены несколькими составмяющими (рис. 5):

1. Что? - это убытки, которые могут нести обе стороны экоконфликтов. Эти убытки могут иметь Аенежный эквивалент (то есть, сколько теряет предприятие от экоконфликтов, Аен. еА., или сколько вреАа будет нанесено природе, Аен. еА.)

2. ГАе? - пиощаАь проявмения экоконфликта - то есть на какой территории возник экоконфцикт и его распространение с течением времени;

3. КогАа? - это промежуток времени, где

$\mathrm{t}_{1}$ - начало экоконфмикта;

$\mathrm{t}_{\mathrm{n}}$ - окончание экоконфмикта;

$t_{n-1}-$ срок продления экоконфликта, что вкАючает в себя обострение и разрешения конфмикта.

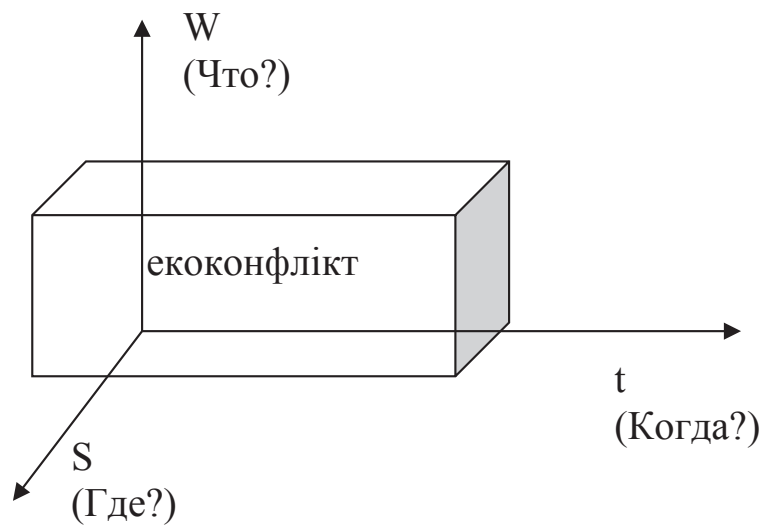

Рис. 5. Границы экомогического конфмикта 
Возникновение экоконфмиктов может быть обусловлено рядом противоречий, которые обусловлены сосуществованием человека с природой. Необходимо отметить, что, человек (преАприятие) могут быть не только причиной экоконфмиктов, но и его решением, то есть наоборот, не причиной, а резумьтатом. Не все взаимоотношения человека и природы могут вызывать экоконфликт, потому, что есть допустимые нормы вмешательства человека в экосистему, но необходимо отметить, что экоконфмикт может возникнуть и без вмешательства человека (природные кризисные явления - торнаАо, наводнения и Ар.

\section{5. Преодомение экоконфмикта}

Анализируя экоконфликты и их преодоления, мы можем определить, что оба субъекта экоконфликта (человек и природа) играют Авойную функцию в создании экоконфмикта и его решении (рис. 6).

\begin{tabular}{|c|c|}
\hline $\begin{array}{c}\text { Причины } \\
\text { экоконфмиктов }\end{array}$ & $\begin{array}{c}\text { Приодоление } \\
\text { экоконфмиктов }\end{array}$ \\
\hline Человек & Человек \\
\hline Природа & Природа \\
\hline
\end{tabular}

Рис. 6. преодоление экоконфмиктов

КогАа оба субъекта экоконфликта (человек (общество) и природа) самостоятельно регулируют экоконфликт - это кучший вариант, потому что не надо задействовать государственные инструменты власти Аля решения такого типа экологических конфликтов, то есть мы можем видеть пример саморегулируемых экоконфликтов. Такие конфликты предусматривают интеграцию функций участников экоконфмикта, и характеризуется умением системы к самовосстановлению. Это Аает возможность уменьшить или совсем отказаться от регулирующей функции государства и может быть применена в тех случаях, когда стратегические цели участ- ников экоконфмикта пересекаются. Именно поэтому, исследования возможности саморегулирования экоконфликтов является оАним из основных этапов изучения процесса преодоления экоконфликтов. Это дает возможность выбрать и аАаптировать инструменты саморегулирования экоконфликтов, что в свою очереАь, приведет к привлечению инструментов государства в Аругих, более напряженных аспектах экономики. Можем отметить, что саморегулируемые конфликты это оАин из виАов УАачного управления, предоставмяет возможности принимать важные решения в конкурентной среде созАавая тем самым конкурентные преимущества.

С учетом основных показателей возникновения, развития и решению экоконфмиктов выдемяют экоконфликты на макро- и микроуровне. Безусловно, эта градация обусловлена разной степенью вмияния экоконфликта и приводит к выявлению разАичных подхоАов к решению влияния макро- и микроэкологических конфликтов Аруг на Аруга.

Необходимо отметить, что конфмиктный потенциал экологического фактора, проанализированного в работе Садабаш B.B. (Sabadash, 2009) может быть как основным этапом решения экопроблемы, а именно «точкой перекмючения », что Аает возможность выхода на новый уровень развития взаимодействия природы и общества Аля достижения более эффективных методов сосуществования системы «Общество - Природа»

\section{6. Выводы}

Таким образом, мы можем определить, что развитие и преодоление экоконфмиктов в современных условиях зависит от экономической и политической ситуации в стране. Карта построения экоконфмиктов дает возможность воспользоваться положительным потенциалом экоконфликта Аля развития потенциала региона. Оценивая пределы конфликта, позволит уменьшить экономические затраты на его решения.

\section{References}

Chuprina, N.M. (2015). Ekomarketing u dlyalnostI promislovogo pidpriemstva. Marketing i menedzhment innovatsiy, 1, 231-239.

Joan Martinez-Alier (2002). The Environmentalism of the Poor: a Study of Ecological Conflicts and Valuation Bookcraft (Bath) Ltd., 309 p.

Gerber, J.F., Veuthey, S., Martinez-Alier, J. Linking (2009). Political ecology with ecological economics in tree plantation conflicts in Cameroon and Ecuador. Ecol. Econ., 68 (12), 2885 - 2889.

Laura Westra, Prue Taylor, Agnès Michelot. (2013). Confronting Ecological and Economic Collapse: Ecological Integrity for law, policy and human rights - Fish Books Ltd, 328 p.

Martinez-Alier, J. (2010). Social Metabolism, Ecological Distribution Conflicts, and Valuation Languages. Ecol. Econ. Special Section: Ecological Distribution Conflicts, 153-158

Herman Daly. (2015). Economics for a Full World. The Great Transition, JUN 18. Retrieved from: http://www.resilience.org/stories/2015-06-18/economics-for-a-full-world\#4

Emelyanenko, L.M. (2003). Konfliktologiya. Retrieved from: http://readbookz.com/books/214.html.

Sabadash, V.V. (2012). Konflikti u prirodokoristuvanni: vitoki ekologo-ekonomichnih protirich, konfliktni chinniki, protseduri vregulyuvannya - Lugansk: Vid-vo "NoulIdzh", p. 830-865. 
Petrushenko, M.M. (2012). Ekonomichniy poglyad na ekologichni konflikti: aspekti modelyuvannya. Visnik sotsialno-ekonomichnih doslidzhen, 2: 354-360. Retrieved from: http://nbuv.gov.ua/j-pdf/Vsed_2012_2_59.pdf Anghelache, C. (2011). Management of the environmental risk - an economic-social priority. Theoretical and applied economics. vol. XVIII, 3(556), 117-130.

Sabadash, V.V. (2009). Konfliktniy potentsial ekologichnogo chinnika. Uchenyie zapiski Tavricheskogo natsionalnogo universiteta im. V.I. Vernadskogo. Seriya «Ekonomika i upravlenie», 22 (61): 111-118.

\section{Наталия ЧУПРИНА \\ ПРЕДПОСЫЛКИ И СУЩНОСТЬ ВЫЯВЛЕНИЯ ЭКОЛОГИЧЕСКИХ КОНФЛИКТОВ В ЭКОНОМИКЕ}

Аннотация. Целью работы является исследование природы экологических конфликтов в экономике, которые, при условии глобализации дают возможность (или делают невозможным) решение проблемы по загрязнения и уничтожения всех элементов окружающей среды. Выявление границ экоконфликтов в экономике, которыебудутопределяющимиприформированииихвозможностейиразработкеальтернативных вариантов преодоления экоконфликтов. Методика. Исследование основано на анализе состояния экологической составляющей экономики Украины за последние годы и результатах работы промышленных предприятий страны. Работа промышленных предприятий может провоцировать создание экологических конфликтов. Также использованы результаты научных исследований ведущих ученых в данной области. Результаты исследований дали возможность определить сущность выявления экологических конфликтов в экономике. Проследить развитие и распространение экологических конфликтов в динамике. Разработанная карта построения экологических конфликтов дает возможность более детально проанализировать составляющие экологического конфликта и выработать управленческие действия, направленные на ликвидацию экологического конфликта в экономике. Обоснована необходимость задействования потенциала экологических конфликтов в будущем установив его пределы в экономике. Практическое значение. Проблема экологии, а именно предупреждение или оптимальное решение экоконфликтов является предпосылкой развития страны, как целостного государства со здоровым населением, которое может жить в стране и свободно пользоваться ее ресурсами (в пределах законодательных актов). Однако, преодолению экоконфликтов не уделяется достаточно внимания как на государственном, так и на местном уровне. Основные этапы анализа и возможные варианты развития экоконфликтов становятся основой для формирования государственных приоритетов в направлении экологизации основных отраслей производства в экономике. Особенности возникновения каждого отдельного экологического конфликта, осуществление исследований по этой проблеме, систематизация и анализ полученных результатов и путей преодоления экоконфликтов в индустриальной стране - это и должно быть одним из главных приоритетов государства, и, осуществляться, как на микроуровне, так и на макроуровне в экономике. При рассмотрении процессов экологизации, развития и управлением экологической безопасности государства необходимо достаточно подробно описать проявления экоконфликтов, их функции и характерные черты. Вмешательство государства при устранении экоконфликтов должно привести не только к его решению, но и предоставить возможности сосуществования и дальнейшему развитию всех участников экологического конфликта в экономике. Значение/оригинальность. Таким образом, мы можем определить, что развитие и преодоление экоконфликтов в современных условиях зависит от экономической и политической ситуации в стране. Карта построения экологических конфликтов дает возможность воспользоваться положительным потенциалом экологических конфликта для развития потенциала региона. Оценивая пределы конфликта, позволит уменьшить экономические затраты на его решения. 